\title{
Zinc Oxide Nanostructures for Efficient Energy Conversion in Organic Solar Cell
}

\author{
M.F. Nurfazliana*, S.A. Kamaruddin, M.S. Alias, N. Nafarizal, H. Saim and M.Z. Sahdan \\ Microelectronic and Nanotechnology - Shamsuddin Research Center, Universiti Tun Hussein Onn Malaysia, \\ 86400 Parit Raja, Batu Pahat, Johor, Malaysia
}

\begin{abstract}
We present a new approach of solution-processed using zinc oxide $(\mathrm{ZnO})$ nanostructures as extraction layer material for organic solar cells. It is low chemical reaction compatibility with all types of organic blends and its good adhesion to both surfaces of ITO/glass substrate and the active layer (blends). Parameters such as the thickness and the morphology of the films were investigated to prove that these factors greatly affect the efficiency of organic solar cells. In this work, ZnO layer with thickness of approximately $53 \mathrm{~nm}$ was used as an interlayer to prevent pin-holes between the electrode and the polymer layer. The polymer layer was coated on the ZnO layer with the thickness of about $150 \mathrm{~nm}$. The thick polymer layer will form a non-uniform surface because of the solvent, 1-2dichlorobenzene will etch away some region of the polymer layer and forming pin-holes. ZnO nanostructures layer was used to prevent pin-holes between the polymer layer and electrode. From the surface morphology of $\mathrm{ZnO}$ layer, it shows a uniform surface with particle grain size obtained between $50-100 \mathrm{~nm}$. The presence of the interlayer has a positive effect on the electrical characteristics of the solar cells. It was found that an organic solar cell with thickness less than $150 \mathrm{~nm}$ shows the optimum performance with efficiency of $0.0067 \%$ and Fill Factor (FF) of about 19.73.
\end{abstract}

Keywords: Nanostructures, extraction layer, pin-holes, poly (3-hexylthiophene) (P3HT), [6,6]-phenyl $\mathrm{C}_{61}$-butyric acid methyl ester (PCBM).

\section{INTRODUCTION}

Over the past decades, much effort has been imposed in order to improved energy efficiency, to develop renewable energy and clean fuel sources, and to reduce overall greenhouse gas emission. In particular, the abundance of clean energy from the sun has drawn much attention [1]. Recently, solutionprocessed organic solar cells have been attracted considerable interests potential next-generation solar cells due to the rapid increased in power conversion efficiency (PCE) towards 10\% (the threshold for commercial production) [2]. They can be processed by simple methods which compatible with mass production and cost effective (flexible) photovoltaic devices, with low environmental load, and as lightweight alternatives to currently used silicon solar cells [2]. The combination of poly (3-hexylthiophene) (P3HT) and [6,6]-phenyl $\mathrm{C}_{61-}$ butyric acid methyl ester (PCBM) in organic blends exhibits particularly promising photovoltaic performance [3]. It was reported by Gang Li et al. on the fabrication of a blend organic solar cells using P3HT and PCBM which produced the significant improvement results from the crystallinity of the blend solution. The best performance from the optimized blend organic solar cells was $4.4 \%$ [4].

*Address correspondence to this author at the Microelectronic and Nanotechnology - Shamsuddin Research Center, Universiti Tun Hussein Onn Malaysia, 86400 Parit Raja, Batu Pahat, Johor, Malaysia; Tel: +607-4538618; Fax: +607-4536060; E-mail: nur_fazliana89@yahoo.com
Basically, the advancements in the field of organic solar cells are strongly driven by development of new materials and device architectures. The electrodes material is one of the important parameter for the organic solar cells operation. Commonly, silver $(\mathrm{Ag})$ or aluminium (AI) and indium tin oxide (ITO) are used as transparent and reflective electrodes. In this work, indium tin oxide (ITO) and gold (Au) was used as transparent and reflective electrodes, respectively.

However, the efficiency of the organic solar cells might suffer of non-optimum interfaces (provides pinholes) between the active layer and the electrodes with such conductors and decreasing short circuit current density $\left(J_{s c}\right)$, open circuit voltage $\left(V_{o c}\right)$ and Fill Factor $(F F)[5]$.

In order to improve the efficiency, stability and optimum interfaces between the electrodes and the active layers, an inverted structure have been demonstrated. One common approach is to use low work function metals such as $\mathrm{Sm}, \mathrm{Ca}$ or metal oxide such as zinc oxide $(\mathrm{ZnO})$ as the electron extraction layer [6].

In recent years, the use of $\mathrm{ZnO}$ in photovoltaic devices has been expanding. In 2008, a $\mathrm{ZnO}$ electron selective layer was prepared by Kyaw et al. using a solgel process in an inverted organic photovoltaic (OPV) device on a glass substrate to achieve a PCE of $3.09 \%$ [7]. Then, $\mathrm{Hau}$ et al. adopted spin-coated $\mathrm{ZnO}$ nanoparticles as the electron selective layer for 
inverted OPV devices fabricated on a glass and plastic substrates, respectively. The maximum PCEs of $3.78 \%$ and $3.58 \%$ were achieved [6]. In addition, Krebs et al. produced solution-processed $\mathrm{ZnO}$ which was successfully applied to roll-to-roll processing for inverted PV devices [8]. The $\mathrm{ZnO}$ nanorods can improve the electron transport in bulk-heterojunction solar cells and it was reported by Takanezawa et al. [9].

The aim of this work is to study the effect of $\mathrm{ZnO}$ nanostructures for efficient energy conversion in organic solar cells. The $\mathrm{ZnO}$ is use as the acceptorelectrode interface and the energy band will be aligned to have enough lifetime and energy for the carrier transport for the polymer layers. The organic blend of P3HT and PCBM was used as the polymer layer.

\section{SUBSTRATE PREPARATION}

Indium tin oxide (sheet resistance of $10 \Omega / \mathrm{sq}$ ) coated on a glass substrate $(20 \mathrm{~mm} \times 20 \mathrm{~mm})$ was cleaned in ultra-sonic baths with acetone, ethanol, and rinsed with DI water for $20 \mathrm{~min}$, respectively. Then, the substrate was slowly dried with high purity nitrogen gas. The etching process was applied to etch away the unwanted ITO coated glass region on the substrate. The ITO coated glass was coated with mask to protect the conductive region while the unwanted region was left unprotected. It was dipped into hydrofluoric (HF) acid for 1 minute. Then, the substrate was rinsed-off into de-ionized (DI) water and dried in ambient. After that, the electrical contact between ITO-trench-ITO was measured using multimeter in order to ensure either the etching was completed.

\section{EXPERIMENTS}

There are two solutions prepared to fabricate the organic solar cell which are (i) ZnO thin film and (ii) organic thin film. Figure $\mathbf{1} \mathbf{a}-\mathbf{b}$ shows the substrate containing the $\mathrm{ZnO}$ and polymer layer. For solution (i), an aqueous solution containing same molarity of zinc acetate dehydrates $\left[\mathrm{Zn}\left(\mathrm{O}_{2} \mathrm{CCH}_{3}\right)_{2}\left(\mathrm{H}_{2} \mathrm{O}\right)_{2}\right]$ and monoethanolamine $\left[\mathrm{H}_{2} \mathrm{~N}-\mathrm{CH}_{2} \mathrm{CH}_{2} \mathrm{OH}\right]$ was diluted in $30 \mathrm{ml}$ of isopropyl alcohol (IPA). The solution was aged and stirred for 24 hours at room temperature. Then, spin coating technique was used to deposit the $\mathrm{ZnO}$ layer and preheated the sample at $280{ }^{\circ} \mathrm{C}$ in 3 minutes. After that, annealed the sample at $500^{\circ} \mathrm{C}$ for 1 hour and cooled down at room temperature.

For solution (ii), an aqueous solution containing of P3HT:PCBM powder with the same molarity $1: 1$ was diluted in $1 \mathrm{ml} 1$-2dichlorobenzene. The solution was stirred and aged for 24 hours at room temperature. After that, the polymer layer was deposited using spin coating technique for $10,8,4$ and 1 layers. Then, the sample was preheated at $60{ }^{\circ} \mathrm{C}$ for 5 minutes and annealed at $500^{\circ} \mathrm{C}, 3$ minutes later for 1 hour.

Finally, the electrode was deposited on the polymer layer using a d.c. sputter coater assisted by mask. The material used is gold $(\mathrm{Au})$. The metal

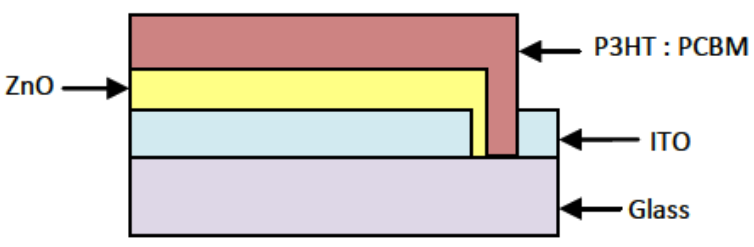

(b)

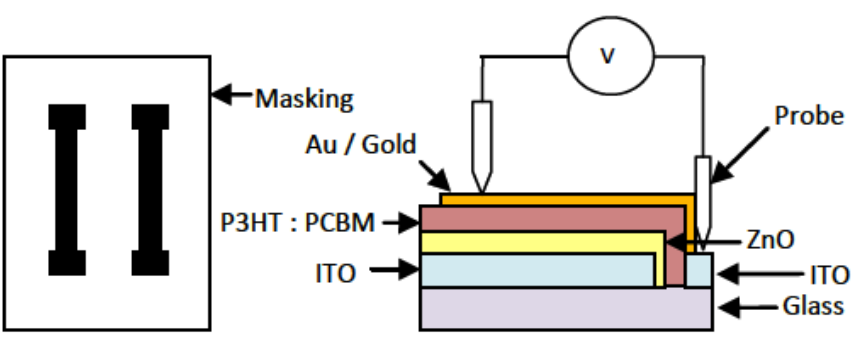

(c)

Figure 1: The configuration; (a) ZnO layer; (b) polymer layer (P3HT:PCBM); (c) The electrode masking and $I-V$ measurement setup. 
electrode was deposited at $40 \mathrm{~mA}$ for 200 seconds and the thickness formed was approximate to $100 \mathrm{~nm}$. The metal electrode masking is shown in Figure 1c.

The P3HT:PCBM thin films was characterized into three types of characterization which are thickness analysis, surface topology and electrical properties. The thickness measuring analysis of the polymer layer was done using a surface profiler (KLA Tencor) at scan length and scan speed of $3000 \mathrm{~mm}^{2}$ and $50 \mu \mathrm{s}$, respectively. The morphology of the thin film was observed using an atomic force microscope, AFM (XE-100 Park System). The electrical properties were characterized using $I-V$ measurement setup which is shown in Figure 1c. The sample were masked and coated with gold $(\mathrm{Au})$ using d.c. sputter coater. The probes were placed on the two electrodes which are ITO and gold $(\mathrm{Au})$ surfaces. The characterization of $\mathrm{ZnO}$ structures was done using a field emission scanning electron microscopy, FE-SEM (JEOL JSM7600F).

\section{RESULTS AND DISCUSSION}

Etching process isolates the ITO coated glass into two parts which are anode and cathode in order to prevent short circuit. Figure 2a shows the surface of ITO coated glass substrate after etching process. It is seen that the white trench is actually the glass surface where the ITO has been removed through etching process.

Figure $\mathbf{2 b}$ indicates the field emission scanning electron microscope (FESEM) results of $\mathrm{ZnO}$ layer at 100,000 magnifications. The image of $\mathrm{ZnO}$ particles shows that the diameters of the particles are in the range of $50 \mathrm{~nm}$ to $100 \mathrm{~nm}$ (considered as nanostructures) [10]. $\mathrm{ZnO}$ act as a charge collector where electrons will be collected and accumulated before moving to the ITO electrodes [10].

The thicknesses of the P3HT:PCBM layer are listed in Table 1. By reducing the coating times, the thicknesses of polymer obtained were differ and labeled by $A, B, C$ and $D$.

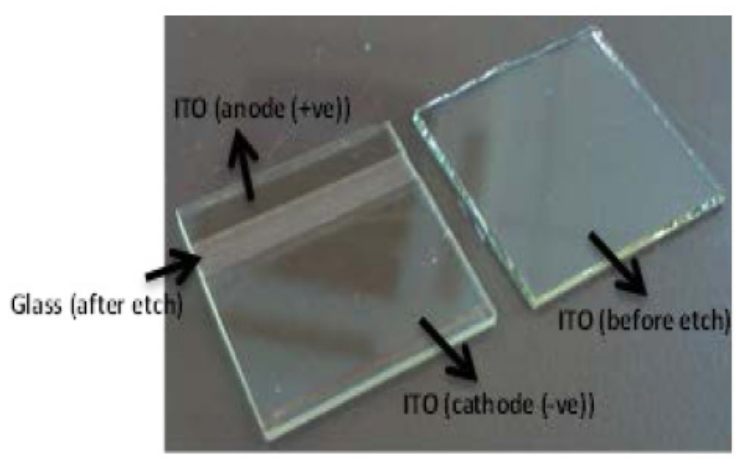

(a)

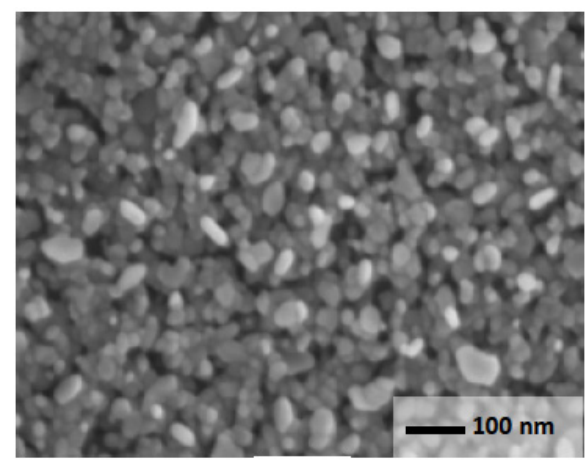

(b)

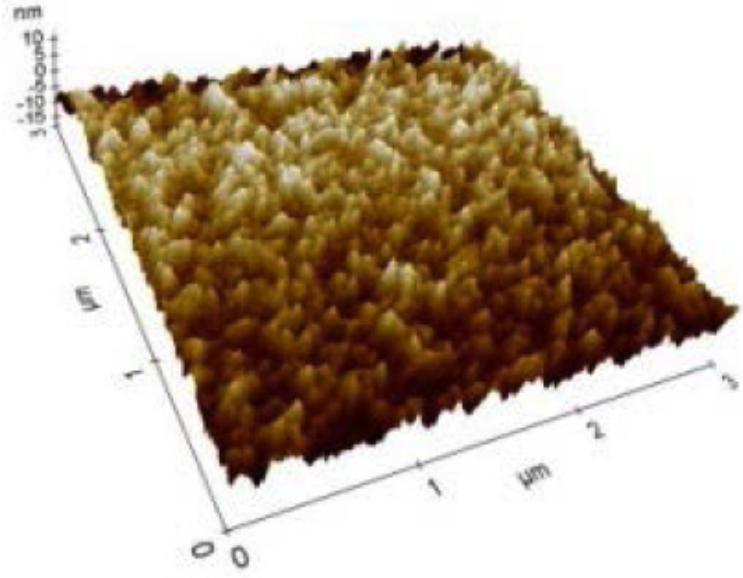

(c)

Figure 2: (a) Substrate after etch; (b) The ZnO layer structures at 100,000 magnifications; (c) The morphology of P3HT:PCBM after anneal. 
Table 1: Thickness Results

\begin{tabular}{|c|c|c|}
\hline Sample & Coating & Thickness \\
\hline \hline A & 10 times & $272.62 \mathrm{~nm}$ \\
\hline B & 8 times & $209.74 \mathrm{~nm}$ \\
\hline C & 4 times & $163.57 \mathrm{~nm}$ \\
\hline D & 1 times & $150 \mathrm{~nm}$ \\
\hline
\end{tabular}

The morphology of the thin film may relate to the performance of organic solar cells. In order to understand the morphological effect before and after applying an annealing or heating to the thin film, we used the atomic force microscopy (AFM) to probe the device surfaces. Figure 2c shows the AFM results of $\mathrm{P} 3 \mathrm{HT}$ :PCBM after annealing. The roughness of the thin film is $6.29 \mathrm{~nm}$. From the results obtained, it shows that the P3HT:PCBM film is stable and uniform. By applying heat energy, the polymer material would expand depending on its thermal expansion coefficient. The surface become smoother and the crystal will be rearranged.

Figure 3a-b shows the current-voltage (I-V) characteristics of organic solar cell using different thickness. Sample A and B which have organic layer thicknesses of $272.62 \mathrm{~nm}$ and $209.74 \mathrm{~nm}$ indicate an ohmic behaviour showing that, there is a short circuit between Au and ITO.

On the other hand, sample $C$ which has organic layer thickness of $163.57 \mathrm{~nm}$ shows an open circuit voltage $\left(V_{o c}\right)$ which indicates that a solar cell has been

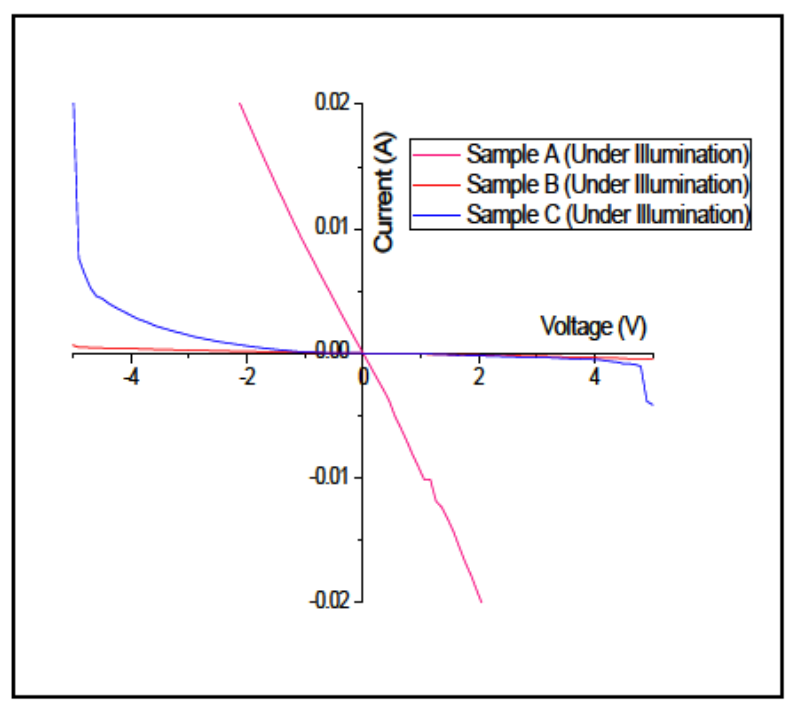

(a) formed. However, there is no efficiency. Sample D which has organic layer thickness $150 \mathrm{~nm}$ shows a short circuit current density $\left(J_{s c}\right)$ of $0.287 \mathrm{~mA} / \mathrm{cm}^{2}$ and open circuit voltage $\left(V_{o c}\right)$ of $0.111 \mathrm{~V}$.

The efficiency $(\eta)$ and Fill Factor (FF) of this organic solar cell are $0.0067 \%$ and 19.73 , respectively. Therefore, we could propose a mechanism explaining the reason of how a solar cell was formed.

The mechanism of the organic solar cell behavior is shown in Figure 4a-c. Figure 4a shows the polymer layer deposited using only 1 layer. Since the polymer layer is thin, the exciton will diffuse and has enough life-time to arrive at the metal electrode. Therefore, the solar cell was formed and the efficiency was obtained. Figure $\mathbf{4 b}$ shows a thick polymer layer resulted from 10 times deposition. Since the polymer is easily dissolved in 1-2dichlorobenzene, the resulting film was not uniform and some of the region was etched away during spin coating which forming pin-holes as indicates in Figure 4c. Pin-hole that occurs on the substrate will cause short circuit between polymer and the substrate resulting an ohmic behavior. This phenomenon is applied to sample A and B. When the coating times were reduced, the formation of pin-hole also reduced. Thus, creating more homogenous thickness film and increasing the possibility of solar cell formation.

\section{CONCLUSION}

The aim of this study was to examine the effect of $\mathrm{ZnO}$ nanostructures for efficient energy conversion in

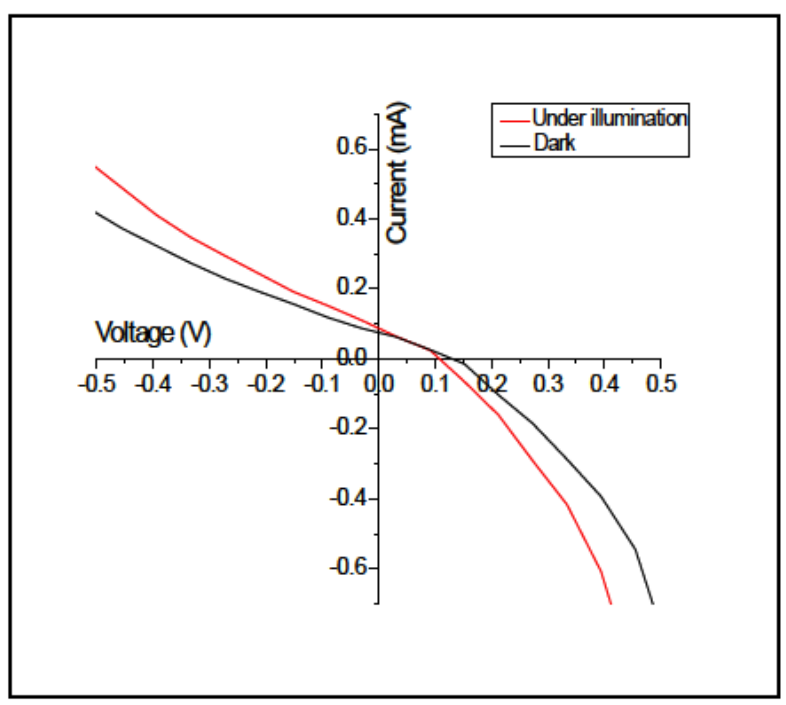

(b)

Figure 3: I-V characteristics of P3HT:PCBM; (a) Sample A and B shows an Ohmic curve while sample C shows a Schottky curve; (b) Organic solar cell curve. 


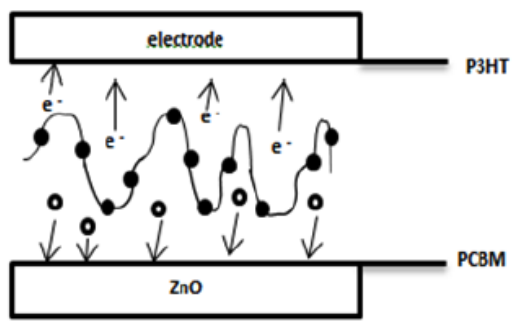

(a)

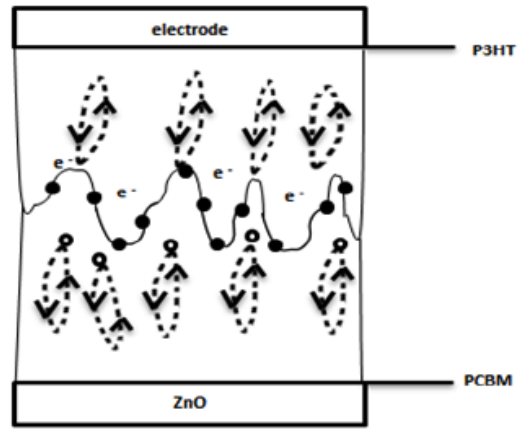

(b)

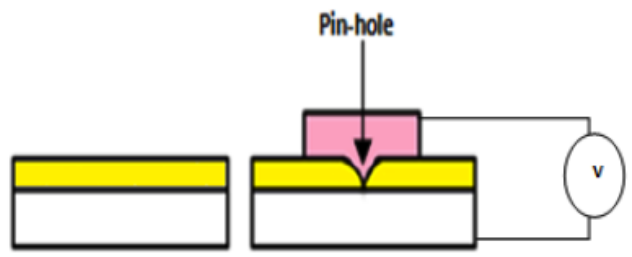

(c)

Figure 4: The mechanism of polymer layer; (a) Thin polymer layer; (b) Thick polymer layer; (c) Polymer layer with or without pin-hole.

organic solar cells. We have successfully developed a solution-processed $\mathrm{ZnO}$ layer as interlayer for organic solar cells through a simple and low-cost method which is spin coating. The solution-processed $\mathrm{ZnO}$ interlayer effectively block holes and collect electrons from the active layer (P3HT:PCBM). It was found that, organic solar cell has been formed and shows the optimum performance with efficiency of $0.0067 \%$ and Fill Factor of 19.73. The optimum thickness of the active layer was observed in order to improve the performance of organic solar cells. In conclusion, the effects of $\mathrm{ZnO}$ nanostructures were highly influence the stability and efficiency of organic solar cells. This is due to the function of the interlayer to provide a hole blocking capability for efficient electron extraction on the active layer (P3HT:PCBM).

\section{ACKNOWLEDGEMENTS}

A special thanks to Universiti Tun Hussein Onn Malaysia (UTHM) and Ministry of Education (MoE) for the financial support through Fundamental Research Grant Scheme (FRGS) Vote 1059 and 1210.

\section{REFERENCES}

[1] Yang X, et al. Enhancement of Photocurrent in Ferroelectric Films Via the Incorporation of Narrow Bandgap Nanoparticles. Adv Mater 2012; 24: 1202-208. http://dx.doi.org/10.1002/adma.201104078
[2] Hou J, et al. Synthesis of a Low Band Gap Polymer and Its Application in Highly Efficient Polymer Solar Cells. J Am Chem Soc 2009; 131: 15586-87.

[3] Boix PP, et al. Role of $\mathrm{ZnO}$ Electron-Selective Layers in Regular and Inverted Bulk Heterojunction Solar Cells. J Phys Chem Lett 2011; 2: 407-11.

[4] Li G, et al. High-efficiency solution processable polymer photovoltaic cells by self-organization of polymer blends. Nat Mater 2005; 4: 864-68. http://dx.doi.org/10.1038/nmat1500

[5] Meyer J, et al. Transition Metal Oxides for Organic Electronics: Energetics, Device Physics and Applications. Adv Mater 2012; 24: 5408-27. http://dx.doi.org/10.1002/adma.201201630

[6] Qian L, et al. Hybrid polymer-CdSe solar cells with a $\mathrm{ZnO}$ nanoparticle buffer layer for improved efficiency and lifetime. J Mater Chem 2011; 21: 3814-17. http://dx.doi.org/10.1039/c0jm03799k

[7] Zhao D, et al. Efficient tandem organic solar cells with an Al/MoO intermediate layer. Appl Phys Lett 2008; 93: 083305. http://dx.doi.org/10.1063/1.2976126

[8] Jørgensen $M$, et al. Stability/degradation of polymer solar cells. Solar Energy Mater Solar Cells 2008; 92: 686-14. http://dx.doi.org/10.1016/j.solmat.2008.01.005

[9] Takanezawa K, et al. Efficiency enhancement of polymer photovoltaic devices hybridized with $\mathrm{ZnO}$ nanorod arrays by the introduction of a vanadium oxide buffer layer. Appl Phys Lett 2008; 93: 063308. http://dx.doi.org/10.1063/1.2972113

[10] Schmidt-Mende L, MacManus-Driscoll JL. ZnOnanostructures, defects, and devices. Mater Today 2007; 10: 40-48.

http://dx.doi.org/10.1016/S1369-7021(07)70078-0

(c) 2014 Nurfazliana et al.; Licensee Lifescience Global.

This is an open access article licensed under the terms of the Creative Commons Attribution Non-Commercial License (http://creativecommons.org/licenses/by-nc/3.0/) which permits unrestricted, non-commercial use, distribution and reproduction in any medium, provided the work is properly cited. 